\title{
Cost-of-illness study of type 2 diabetes mellitus in Colombia
}

\author{
Juan Camilo González, ${ }^{1}$ John H. Walker, ${ }^{2}$ \\ and Thomas R. Einarson ${ }^{3}$
} $\begin{array}{ll}\text { Suggested citation } & \text { González JC, Walker JH, Einarson TR. Cost-of-illness study of type } 2 \text { diabetes mellitus in Colombia. } \\ \text { Rev Panam Salud Publica. 2009;26(1):55-63. }\end{array}$

ABSTRACT Objective. To determine the per patient and overall cost of illness of type 2 diabetes mellitus (T2DM) in Colombia from Ministry of Health and societal perspectives.

Methods. A published Markov transition model was adapted for Colombia, using the clinical expertise of a Colombian endocrinologist. Transition probabilities for the model were derived from an international literature review. A model was run for a time horizon of 42 years. Direct resources (drugs, laboratory, medical, hospital, other health care) were identified and cost was ascertained by using national price lists, international health care guidelines, and other Colombian studies or data from other countries. Indirect costs (work time lost) were calculated by using the human capital approach. Annual and lifetime direct and indirect costs, in 2007 U.S. dollars with a 5\% discount rate, were determined on a per patient basis and projected to the overall Colombian population. Costs were clustered according to treatments and outcomes.

Results. The estimated annual cost was $\$ 2.7$ billion from the societal perspective and $\$ 921$ million from the Ministry of Health perspective. The annual direct cost per patient was $\$ 288$, and the indirect cost was $\$ 559$ (total $=\$ 847$ ). This cost was distributed across disease outcomes as follows: diabetes treatment (drugs), 47\%; cardiac and coronary disease, $24 \%$; stroke, $15 \%$; amputation, $9 \%$; nephropathy, 3\%; retinopathy, 2\%. Macrovascular complications made up $86 \%$ of the annual direct costs and $95 \%$ of the annual indirect costs of T2DM.

Conclusions. We estimated the annual cost of T2DM for Colombia from societal, Ministry of Health, and Colombian Health System perspectives. We also estimated annual direct cost per patient and the cost of treating diabetes and macrovascular complications. The economic burden is substantial and comparable to results for other countries. The model showed a logical disease progression.

Key words Burden of illness, cost of illness, diabetes mellitus, Colombia, Latin America.

Diabetes mellitus (DM) is a chronic disease that is widespread. It has been estimated that more than 180 million people worldwide are affected, and this

\footnotetext{
1 Merck Sharp \& Dohme, Bogotá, Colombia.

2 Brock University, Faculty of Business, St. Catharines, Ontario, Canada.

3 Leslie Dan Faculty of Pharmacy, University of Toronto, Toronto, Ontario, Canada. Send correspondence and reprint requests to: Thomas R. Einarson, Leslie Dan Faculty of Pharmacy, University of Toronto, 144 College Street, Toronto, Ontario M5S 3M2, Canada; phone: 416-978-6212; fax: 416-978-8511; e-mail: t.einarson@utoronto.ca
}

number is predicted to more than double by 2030 (1). This disease is associated with substantial morbidity and mortality. For example, in 2005, an estimated 1.1 million people died from DM and almost $80 \%$ of diabetes deaths occurred in low- and middle-income countries (1).

Type $2 \mathrm{DM}$ (T2DM) is a chronic disease characterized by hyperglycemia and dyslipidemia due to underlying insulin resistance. The condition commonly progresses to include microvascular (e.g., retinopathy, nephropathy, neuropathy) and macrovascular (e.g., heart, cerebral, and peripheral vascular disease) complications $(2,3)$. Wannamethee et al. reported that macrovascular complications are the most common and are responsible for almost $70 \%$ of the deaths in diabetic patients dying from heart disease (4). Grundy et al. determined that mortality in chronic kidney disease exceeded $20 \%$ per year in patients with diabetes and that cardiovascular disease is the leading cause of death among diabetic patients with end stage renal disease (3). 
The importance of identifying and quantifying the costs and consequences of T2DM is that it will allow us to understand more clearly the economic impact of the disease. Cost-of-illness studies describe the resources used and potential resources lost as a result of a disease. Together with prevalence, incidence, morbidity, and mortality data, these studies help to portray the impact of a disease on society (5). It is important to perform cost-of-illness studies in order to inform clinical decision making, develop policies and guidelines, and effectively allocate resources.

Cost-of-illness studies of T2DM published in the international literature have used two methodologic approaches. The first is the prevalence-based approach in which the costs of diabetes are estimated for a specific period of time (usually 1 year) for a specified cohort of diabetic patients. The second is the incidencebased approach to determine the costs of diabetes for a cohort of patients, usually from diagnosis until death. The prevalence approach estimates the burden of disease for a determined period of time and is normally cross-sectional, while the incidence-based approach provides longitudinal information of the costs over a lifetime (6).

A number of methodologies are available when taking a prevalence-based approach. Studies based on combined population data are most often used and, in diabetes, the data (e.g., primary diagnosis, complications) are grouped according to diagnostic codes, such as the International Classification of Diseases. As an example of a study that used this approach, Oliva et al. determined that the direct costs for patients with DM in Spain were between $€ 2.4$ and $€ 2.675$ billion for the year 2002 (7). Another example was an American study by Taylor, who estimated a direct cost for T2DM of $\$ 6.9$ billion from a national survey of health expenses during 1997 (8). At the international level, the CODE-2 study was performed in eight European countries using a prevalence-based approach, gathering data by means of written surveys and interviews (9). In Spain, the latter study used retrospective collection of data from medical records to examine resource consumption and found an annual health care cost per patient of $€ 1,305$ for 1999. Additionally, the authors of that study separated costs associated with each major complication (10).
From the studies based on the incidence approach, two are highlighted. In Spain, Hart et al. created a simulation model to determine the current and future direct costs of a group of patients diagnosed with diabetes in 1997. They estimated an average lifetime cost of 5.1 million pesetas (approximately U.S. $\$ 42300$ in 1997) per patient (11). In the second study, conducted in 1994 by Stern and Levy, the direct costs of treatment of a patient with type $1 \mathrm{DM}$ were considered over a period of 35 years. They determined a mean lifetime cost of $£ 104000$ per person (12).

The prevalence of T2DM in Colombia is just over $7.5 \%$ (13). The disease imposes a tremendous burden in terms of human suffering, making it and its associated clinical and economic consequences a major public health problem (14). Despite the chronic nature of DM and its devastating consequences, its economic impact in Colombia is unknown. No cost-of-illness studies have been published in Colombia. Therefore, this study was undertaken to fill that gap in our knowledge.

Our objective was twofold. First, we wanted to determine the average cost of treating an individual with T2DM in Colombia, including the direct and indirect costs associated with the disease and its consequences. Our second objective was to extrapolate these costs to the entire population of the country. The viewpoints of interest were those of the Ministry of Health as payer and of society. Specific objectives were to identify the stages or health care states that a patient experiences during the course of the disease, to determine the probability of each event over time, to identify resources consumed in each of the stages, to identify the cost of the resources consumed, to calculate the overall lifetime cost of T2DM per patient, to examine the robustness of the results, and to extrapolate these results to the population of Colombia to estimate the total cost burden due to this disease.

\section{METHODS}

The primary perspective for this study was that of the Colombian Ministry of Health as payer. Included in the analysis were all direct costs including drugs, medical care, hospitalization, laboratory services, and services of other health care professionals. The secondary perspec- tive was that of society in Colombia. As well as direct costs, the analysis from the latter perspective incorporated indirect costs. These costs included loss of productivity due to the disease, permanent loss due to disease progression, and labor loss due to death and disability.

\section{Colombian Markov model}

A Markov model (Figure 1) was created to analyze all the relevant stages in the progression of the disease. This model contained the stages in the disease progression that have a major impact in Latin America, according to the study by Barceló and colleagues (15). These stages included amputation, retinopathy, cardiovascular disease, nephropathy, neuropathy, and peripheral vascular disease as complications. In this model, cardiovascular disease included cardiac (i.e., congestive heart failure) and coronary (i.e., myocardial infarction) disease. We followed the recommendations of the International Diabetes Federation (16). Adaptation to Colombia was done with the input of a local diabetologist/ endocrinologist.

Markov models assume that a patient is always in one of a finite number of discrete health states, called Markov states. All events are represented as transitions from one state. As people progress through the simulation model from the onset of diabetes to death, they can develop five types of complications: nephropathy, neuropathy, retinopathy, coronary heart disease, and stroke. People can die of some of these complications or of other causes. The model includes transition probabilities between disease stages on each of the five complication paths. Although it is possible (and may often occur) that patients have more than one complication simultaneously, those states were not included for the sake of simplicity. Consequently, there could be some minor underestimation of costs.

We used an incidence-based model over the lifetime of a typical patient with T2DM. The model began when the patient was diagnosed with the disease at age 40 . We used this age, since a survey by Barceló and Rajpathak (17) reported a prevalence of $8.1 \%$ in Colombians aged 35-64 years. In consultation with local clinical experts, we decided to begin the model at age 40. It continued until the patient reached the average age at death for a person in this country, which is 72 
FIGURE 1. Markov model for diabetes in Colombia

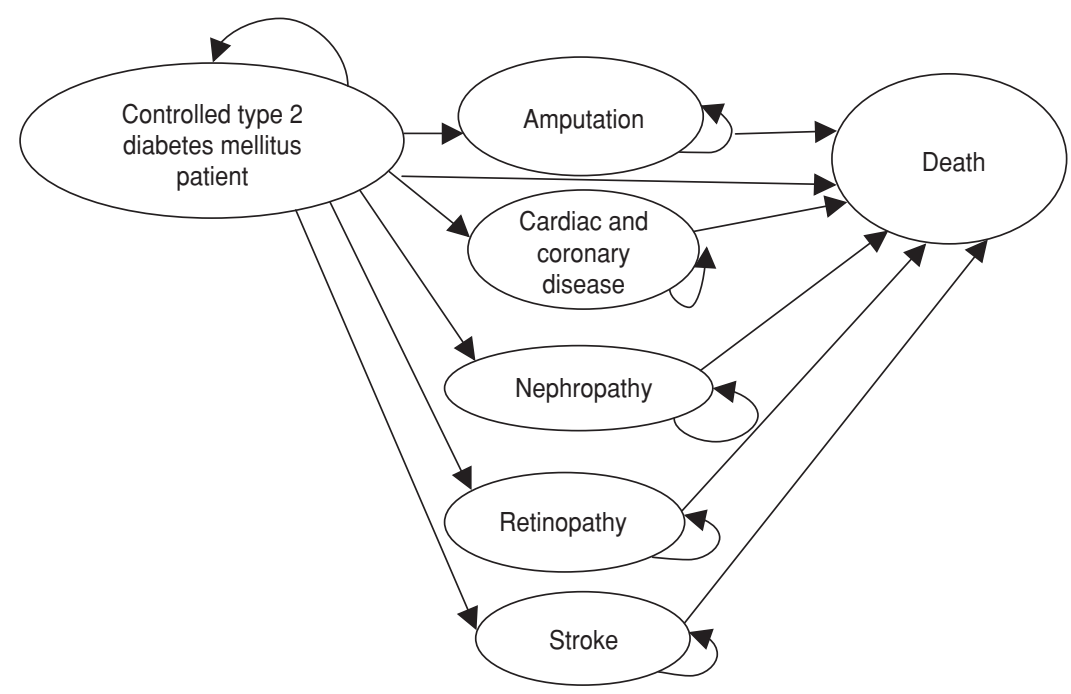

TABLE 1. Type of progressions, submodels, and probabilities of transition used in the model

\begin{tabular}{|c|c|c|c|}
\hline Type of progression & Submodel description ${ }^{\mathrm{a}}$ & $\begin{array}{l}\text { Transition } \\
\text { probability }\end{array}$ & Reference \\
\hline \multirow{2}{*}{ Controlled T2DM ${ }^{b}$} & Transition probability for T2DM with oral therapy & 0.10 & 20 \\
\hline & Transition probability for T2DM with insulin therapy & 0.023 & 20 \\
\hline $\begin{array}{l}\text { Cardiac and } \\
\text { coronary disease }\end{array}$ & $\begin{array}{l}\text { Transition probability for congestive heart failure, } \\
\text { acute myocardial infarction, fatal acute myocardial } \\
\text { infarction, cardiac arrest, and fatal cardiac arrest }\end{array}$ & 0.0331 & $21-23$ \\
\hline Nephropathy & $\begin{array}{l}\text { Transition probability for nephropathy, ESRD } \\
\text { with dialysis, ESRD with transplant, adjusted } \\
\text { by sex and age }\end{array}$ & 0.0016 & 21,23 \\
\hline Amputation & Transition probability for amputation & 0.0022 & 22 \\
\hline Retinopathy & Transition probability for retinopathy & 0.0029 & 21 \\
\hline Stroke & Transition probability for stroke and fatal stroke & 0.0112 & 21,22 \\
\hline
\end{tabular}

a Transition probabilities correspond to the incidence in the first year of diagnosis.

b T2DM = type 2 diabetes mellitus, ESRD = end stage renal disease.

years (5). Statistics from age of onset until death (40-72 years) were age adjusted for survival using published life tables for Colombia (18). The same procedure was performed to estimate death due to disease progression as was done in the study by Clarke et al. (19). This calculation allowed us to estimate the probability for any time in the disease stage. Table 1 lists the transition probabilities that we entered into the model (20-23).

The analysis (including Monte Carlo simulations) was performed using TreeAge Pro 2007 Suite ${ }^{\circledR}$ software. We estimated the proportions of patients with various complications (e.g., kidney failure, blindness, infection, diabetic foot, compromised peripheral circulation) and how long it took to develop each of these complications. We compared the final model with that developed by Zhou et al. (24) on which this model was based.
We obtained clinical data to populate the model from a variety of sources. The first choice was to use information derived from national statistics of Colombia, the Ministry of Health, local diabetes societies, and local publications. If we could not find information specific to Colombia, then we used data from other Latin American countries or from the Pan American Health Organization. Otherwise, data were obtained and adapted from international literature. This decision was in agreement with the point of view of the Colombian expert, who confirmed that the incidence of diabetes is very similar among populations and that differences lie basically in the age of diagnosis of the disease.

Table 1 shows the different submodels that are included in the analysis as well as the different health conditions embraced in each of them. The transition probabili- ties are based on different clinical studies and vary with time and the risk profile of the study population. Each cycle in this model had a term of 1 year.

\section{Determining costs}

The complexity in determining the costs and resources used in patients with T2DM in this country was the greatest challenge we faced because of the small number of studies or the availability of specific data. However, to obtain a cost approximation, we estimated the annual cost of the diabetes treatment and its complications for a patient.

Cost was done in 2007 Colombian pesos (U.S. \$1 = 2121 Colombian pesos) as well as U.S. dollars, with costs derived from price lists of the Ministry of Health. If such lists were not available, then we determined them from other local sources and standard price lists. As a final step, we adapted international costs for Colombia using purchasing power parities (25). Cost and outcomes accrued after 1 year or more were discounted at an annual rate of $5 \%$. The costs are presented in Colombian pesos adjusted by inflation to year 2007 (26-28).

\section{Determining direct costs associated with the disease}

Direct cost of T2DM treatment. We considered two aspects in determining the annual cost to maintain a T2DM patient, which were as follows. First, the minimal standards from the disease management guidelines issued by the International Diabetes Federation, which are broadly accepted and used in patient care, were adapted to identify the resources used (16). Second, a monetary value using the accepted local tariffs adjusted according to inflation to 2007 was assigned (in Colombian pesos). The costs were then converted to U.S. dollars and projected over one full year.

In the model, a patient with T2DM may be initially controlled with diet and exercise, then with oral drugs, and finally with insulin therapy. The annual costs of a patient treated with oral therapy and with insulin were estimated separately (see Table 2$)(29,30)$.

Determining annual treatment costs associated with complications. We searched for local data and publications on the annual costs per patient for each 
TABLE 2. Cost and resource utilization data for treatment of type 2 diabetes in Colombia

\begin{tabular}{|c|c|c|}
\hline Type of therapy & Resource utilization & $\begin{array}{l}\text { Cost, Colombian } \\
\text { pesos } \times 1000^{a}\end{array}$ \\
\hline \multirow{2}{*}{$\begin{array}{l}\text { Screening and } \\
\text { diagnostics (16) }\end{array}$} & Prevention activities & $16(29)$ \\
\hline & Glucose determination & $17(29)$ \\
\hline \multirow[t]{11}{*}{ Care delivery (16) } & Education (31) & $16(29)$ \\
\hline & Health promotion & $6(29)$ \\
\hline & Psychological care & $11(29)$ \\
\hline & Lifestyle management (nutritionist consult) & $12(29)$ \\
\hline & Clinical monitoring ( $\mathrm{HbA} 1 \mathrm{c}^{\mathrm{b}}+$ general consultation) & $83(29)$ \\
\hline & Blood glucose strips & $584(30)$ \\
\hline & Glucose meter equipment ${ }^{c}$ & $26(30)$ \\
\hline & $\begin{array}{l}\text { Cardiovascular risk protection (lipid profile measures, } \\
\text { generic statin) }\end{array}$ & $47(29,30)$ \\
\hline & Renal risk protection (monitoring) (dipstick) & $8(29)$ \\
\hline & $\begin{array}{l}\text { Glucose treatment with metformind (850 milligrams) daily + } \\
\text { sulfonylurea }^{d}\end{array}$ & $1.612(29,30)$ \\
\hline & Total & 2.455 \\
\hline \multirow{11}{*}{$\begin{array}{l}\text { Insulin therapy care } \\
\text { delivery (16) }\end{array}$} & Education & $16(29)$ \\
\hline & Health promotion & $6(29)$ \\
\hline & Psychological care & $11(29)$ \\
\hline & Lifestyle management (nutritionist consult) & $12(29)$ \\
\hline & Clinical monitoring (HbA1c + general consultation) & $83(29)$ \\
\hline & Blood glucose strips & $584(30)$ \\
\hline & Glucose meter equipment $^{c}$ & $26(30)$ \\
\hline & $\begin{array}{l}\text { Cardiovascular risk protection (lipid profile measures, } \\
\text { generic statin) }\end{array}$ & $47(29,30)$ \\
\hline & Renal risk protection (monitoring) (dipstick) & $8(29)$ \\
\hline & Insulin therapy (metformin + insulin $\mathrm{NPH}^{\mathrm{d}}+$ syringe) & $6.340(30)$ \\
\hline & Total & 7.172 \\
\hline
\end{tabular}

a Adjusted for inflation to year 2007 in Colombian pesos (U.S. \$1 = 2121 Colombian pesos) (24-26).

${ }^{\mathrm{b}} \mathrm{HbA} 1 \mathrm{c}=$ glycosylated hemoglobin.

${ }^{c}$ Glucose meter equipment cost amortized over 5 years in Colombian pesos.

${ }^{d}$ Generic drug selected from Colombian price list.

TABLE 3. Cost data for treatment of complications of type 2 diabetes, Colombia (direct and indirect costs)

\begin{tabular}{clr}
\hline Type of cost & \multicolumn{1}{c}{ Event or stage description } & Cost $\times 1000^{\mathrm{a}}$ \\
\hline Cost of progression & Acute myocardial infarction first year & $10073(31)$ \\
& Acute myocardial infarction, subsequent years & $2618(31)$ \\
& Angina, first year of the event & $1118(32)$ \\
& Angina, subsequent years & $468(33)$ \\
& Cardiac failure, first year & $1894(34)$ \\
& Cardiac failure, subsequent years & $359(34)$ \\
& Fatal stroke & $1622(35)$ \\
& Stroke, first year of the event & $2350(35)$ \\
& Stroke, subsequent years & $873(35)$ \\
& Proteinurea (care delivery + ACE inhibitor) $)^{b, c}$ & $2660(16,30,36)$ \\
& Hemodialysis and peritoneal dialysis & $39585(35)$ \\
& Renal transplant, first year & $33000(37)$ \\
& Renal transplant, subsequent years & $4225(38)$ \\
& Lower extremity amputation, first year of event & $7493(11)$ \\
& Retinopathy & $1122(39)$ \\
Cost of productivity loss per year patient < 65 years old & 1051 \\
& Cost of permanent disability (progression diseases) patients & 5539 \\
& $<65$ years & \\
& Cost of productivity loss due to mortality in patients < 65 years & 5539 \\
\hline
\end{tabular}

\footnotetext{
${ }^{a}$ Adjusted for inflation to year 2007 in Colombian pesos (U.S. \$1 = 2121 Colombian pesos) (26-28).

${ }^{b}$ Estimated cost (adapted from International Diabetes Federation (16)) in 2007 Colombian pesos.

${ }^{c} \mathrm{ACE}=$ angiotensin-converting enzyme.
}

stage of disease progression. We found local studies that provided annual costs for acute myocardial infarct (31) as well as for dialysis and renal transplant dur- ing the first year (32). We determined the annual costs of proteinuria treatment using International Diabetes Federation guidelines (16) and local prices (29).
Local data for the other stages of disease progression were not found. Therefore, we adapted comparable costs from Spain, which provided the required information. We did a conversion using purchasing power parity of Colombian pesos (25). Table 3 describes these costs (31-42). To convert to Colombian pesos, we used the United Nations Children's Fund gross national income per capita data for 2005 (43).

\section{Determining indirect costs}

Indirect costs included loss of productivity due to the disease, permanent loss due to disease progression, and labor loss due to death. We estimated cost with the human capital approach, by which we estimated the productivity cost as the future reduction in gross income due to mortality and/or morbidity. This approach estimates potential productivity loss due to reduced remunerated time (40).

In addition, accounting for those people who are not in the labor market was also considered; therefore, leisure time was taken into consideration. For the same reason, an adjustment for the rate of unemployment was not made.

We followed the method described by Mattke and coworkers (40) to estimate productivity losses related to the disease. With this methodology, the first step was to make a salary conversion. We used the gross national income per capita for 2006 (43) converted to 2007 U.S. dollars (44) for this calculation. We estimated impaired ability to work and loss of workdays according to the approach of Mayfield et al. (41). Then, we estimated the cost derived from days lost due to absenteeism and working days with limitations (i.e., presenteeism). We used a maximum working age of 65 years (i.e., retirement age) $(44,45)$, since this approach considers the entire population without correcting for unemployment rates. Thus, we also included leisure time of people who were not employed. Table 3 describes the indirect costs (40-42).

\section{Total cost}

The Markov model calculated the total cost per patient for each analytic perspective. We multiplied these costs by the population of people with T2DM in Colombia to arrive at the overall cost burden. 
FIGURE 2. Markov model for type 2 diabetes mellitus in Colombia

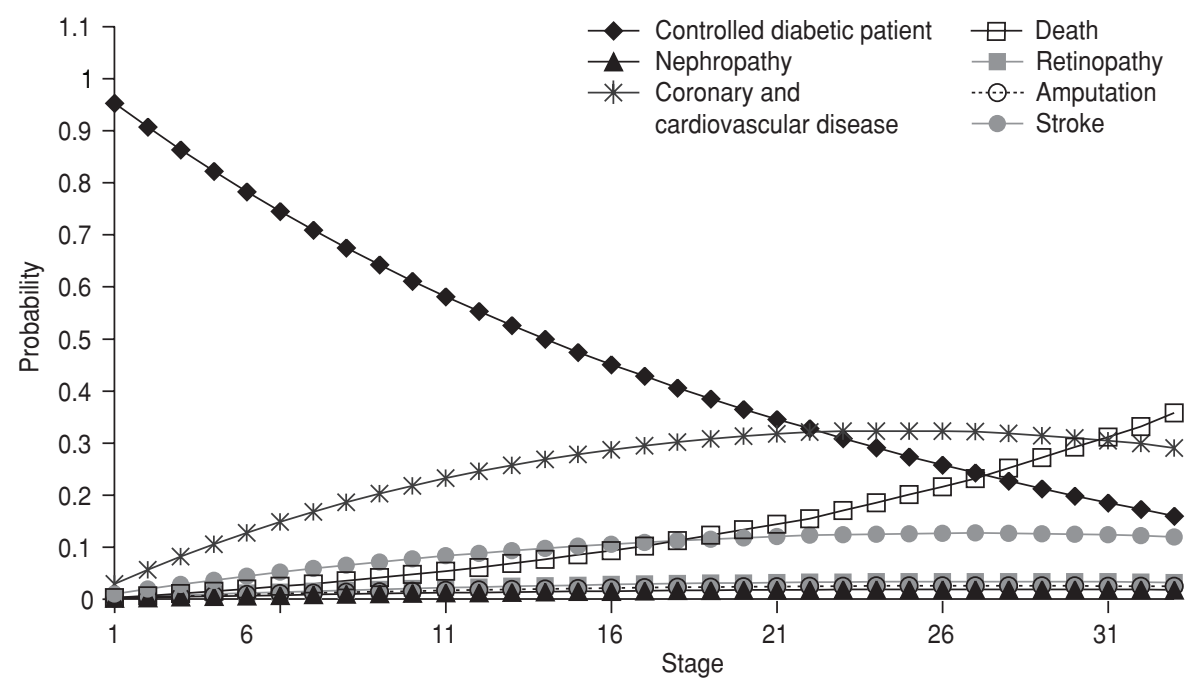

FIGURE 3. Survival curve for type 2 diabetes mellitus in Colombia

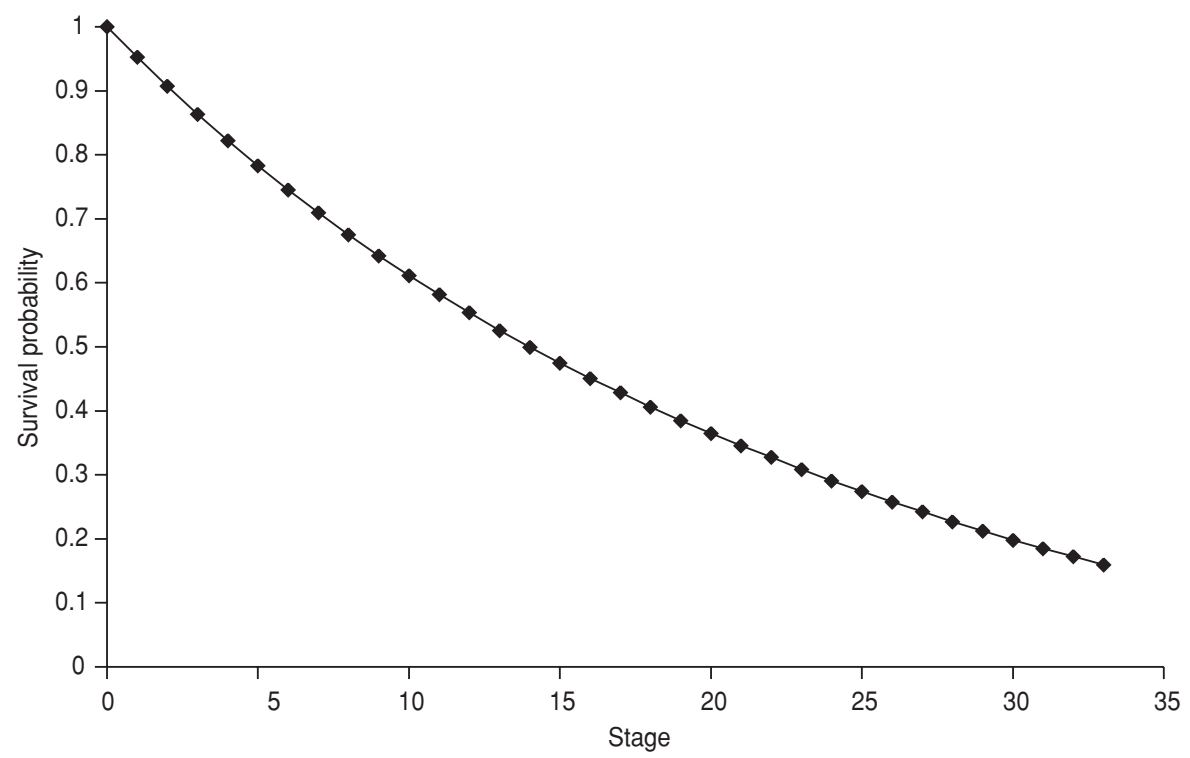

\section{Sensitivity analysis}

Uncertainty about the model's assumptions, variables, and costs was explored with one-way sensitivity analyses. The state "controlled T2DM patient" was selected as a base case. One-way sensitivity analyses were done for all variables, but, because of the large number of variables tested, only the following relevant ones were included: age, discount rate, cost of acute myocardial infarction occurring in the first year, cost of stroke occurring in subsequent years, transition probabilities for "controlled T2DM patient with insulin," congestive heart failure and myocardial infarction, and stroke. Four intervals were used with each variable.

\section{RESULTS}

\section{Outcomes}

Figure 2 presents the estimated risk reduction for a patient who is controlled as the disease progresses as well as the increases in different health state progressions. The survival probability curve of T2DM patients in Colombia was estimated from the first year of diagnosis over a period of 32 years with the disease. This curve is shown in Figure 3. It was estimated that about $15 \%$ of the pa- tients would be alive at year 32 . Table 4 presents the estimated prevalence for T2DM and its complications in the Colombian model compared with the model of Zhou et al. (24).

\section{Estimating the cost of disease per patient}

The cost of T2DM was determined taking into consideration the perspectives of society and of the Ministry of Health as payers. The estimated lifetime cost per patient including both direct and indirect costs (societal perspective) was 57565000 Colombian pesos (U.S. \$27 140). This amount represents an average annual cost per patient of 1784000 Colombian pesos (U.S. \$845) using a discount rate of $5 \%$.

From the perspective of the Ministry of Health as payer, the average cost of T2DM projected for a patient was 19576000 Colombian pesos (U.S. \$9 230) using a discount rate of $5 \%$. This value amounts to an annual cost per patient of 611750 Colombian pesos (U.S. \$288).

The average indirect cost was 37767000 Colombian pesos (U.S. \$17 806) using a discount rate of $5 \%$. That value amounts to an annual cost per patient of 1187000 Colombian pesos (U.S. \$559).

Table 5 summarizes the annual costs (in U.S. dollars) per patient according to the disease stage differentiated into direct and indirect costs. In addition, costs are presented as percentages according to health stage. The stages associated with the greatest costs were diabetes treatment $(47 \%)$, cardiac and coronary diseases $(24 \%)$, and stroke (15\%). Microvascular complications were responsible for the smallest proportion of the total cost.

\section{Cost of disease in Colombia}

The mean cost per year extrapolated to the Colombian population was estimated taking into consideration a prevalence rate of $7.5 \%$ (5) and demographic data (45) for 2007. The estimated mean overall (i.e., direct and indirect) cost attributed to T2DM was 5.7 billion Colombian pesos (U.S. \$2.7 million). Separated according to type, direct costs were $\$ 1.95$ billion Colombian pesos (U.S. \$921 million) and indirect costs were $\$ 3.77$ billion Colombian pesos (U.S. $\$ 1.77$ million). Table 6 summarizes the total costs and their breakdown into indirect costs and 
TABLE 4. Cumulative rates of occurrence for different health stages used in the model

\begin{tabular}{llcc}
\hline \multicolumn{1}{c}{ Progression } & \multicolumn{1}{c}{ Type of progression } & $\begin{array}{c}\text { Colombian model, } \\
\%\end{array}$ & $\begin{array}{c}\text { Zhou model, } \\
\%^{\mathrm{a}}\end{array}$ \\
\hline $\begin{array}{l}\text { Controlled type } 2 \\
\text { diabetes mellitus }\end{array}$ & Diet and exercise, oral therapy, & 47.9 & $17,,^{\mathrm{b}} 23,^{\mathrm{c}} 69^{\mathrm{d}}$ \\
Macrovascular disease & and/or insulin therapy & & 27 \\
& All heart disease & 45.6 & $16.4^{\mathrm{e}}$ \\
& Congestive heart failure & 6.7 & $16.4^{\mathrm{e}}$ \\
& Myocardial infarction & 8.5 & 18.0 \\
Microvascular disease & Stroke & 15.0 & 3.0 \\
& Nephropathy & 1.5 & 3.3 \\
& Retinopathy & 3.2 & 5 \\
\hline
\end{tabular}

a Zhou and colleagues (24) based on the Wisconsin Epidemiologic Study of Diabetic Retinopathy cohort.

b Controlled type 2 diabetes mellitus.

c Type 2 diabetes mellitus treated with oral therapy.

d Type 2 diabetes mellitus treated with insulin therapy.

${ }^{e}$ Combined value for stages.

complications in thousands of dollars for the Colombian population for 2007. Thirty-four percent of the total cost was attributable to direct costs and $66 \%$ to indirect costs.

\section{Sensitivity analyses}

Table 7 presents the outcomes from the sensitivity analyses. We found that results were relatively insensitive to changes in important variables and that the cost of controlled T2DM in patients remained the dominant variable. First, there was a negative relationship between age and cost and probabilities. However, the discount rate had little effect. The cost of a controlled T2DM patient was reduced if age increased; there was a negative relationship between the cost of a controlled T2DM patient and the discount rate.

\section{DISCUSSION}

In this study, we estimated the cost of $\mathrm{T} 2 \mathrm{DM}$ in Colombia using an incidence approach. A Markov model that allowed simulating the progression of diabetes and its complications was developed, which allowed us to predict its longterm impact on patients and the associated costs.

The model was adapted from internationally published studies and it incorporated local disease incidence data. Transition probabilities between disease stages and selected incidence data were validated by a local expert. This process increases both the applicability and certainty of the estimates that we used.

Figure 2 shows the cumulative incidence for each disease stage during the analytic time horizon of 32 years. This graph displays a rational transition of the patient through the various disease stages. As expected, a patient with diabetes in the initial stage has a high probability of being controlled, but as the disease progresses, this probability decreases. Likewise, the probabilities of complications and associated mortality increase during the progression of the disease.

TABLE 5. Direct and indirect annual costs per patient in Colombia in 2007 U.S. dollars and cost proportion per health stage

\begin{tabular}{|c|c|c|c|c|}
\hline Health status & $\begin{array}{l}\text { Direct cost }{ }^{\mathrm{a}} \\
\quad \text { (range) }\end{array}$ & Percent & $\begin{array}{l}\text { Indirect cost } \\
\quad \text { (range) }\end{array}$ & Percent \\
\hline $\begin{array}{l}\text { Controlled type } 2 \text { diabetes } \\
\text { mellitus patient }\end{array}$ & $136.1(114.4,157.7)$ & 47 & $181.5(152.6,210.3)$ & 33 \\
\hline Amputation & $26.9(26.3,27.6)$ & 9 & $20.7(20.2,21.2)$ & 4 \\
\hline Cardiac $^{b}$ and coronary ${ }^{c}$ disease & $69.7(44.3,95.0)$ & 24 & $304.0(193.4,414.7)$ & 55 \\
\hline Nephropathy & $7.3(7.1,7.4)$ & 3 & $3.0(3.0,3.1)$ & 1 \\
\hline Retinopathy & $5.5(5.4,5.7)$ & 2 & $27.3(26.4,28.2)$ & 5 \\
\hline Stroke & $42.9(37.8,48.0)$ & 15 & $19.7(17.3,22.0)$ & 4 \\
\hline Total & 288.4 & 100 & 556.0 & 100 \\
\hline
\end{tabular}

a Costs converted to 2007 U.S. dollars (44).

${ }^{\mathrm{b}}$ Congestive heart failure.

c Myocardial infarction.
Also, a greater impact was observed for macrovascular diseases (e.g., cardiac disease, coronary disease, and stroke). This observation compares well with that from the United Kingdom Prospective Diabetes Study model described by Clarke et al. (19), which used a 12-year horizon but showed a similar magnitude in disease progression (i.e., rates of complications) and mortality.

As shown in the survival curve (Figure 3 ), our mortality rates were somewhat less than those from the model developed by Zhou et al. (24), who estimated a mortality of $51 \%$ at year 10 after diagnosis. Similarly, the Wisconsin Epidemiologic Study of Diabetic Retinopathy (WESRD) cohort reported 55\% mortality. We found a mortality rate of $40 \%$ at year 10, which was $11 \%$ lower than Zhou et al. found and 15\% lower than in the WESRD cohort (24).

An additional analysis of the model was performed by assessing the incidence of complications (Table 4) and comparing them with the results obtained by Zhou et al. (24). Although those authors used a time horizon of 10 years, no great difference was observed in the data obtained from our model, despite our model having a longer time horizon.

The analyses presented above demonstrate that our model was well constructed, has a logical progression through the disease states, and presents a coherent trend that agrees reasonably well with studies previously conducted. Therefore, we consider our cost estimates to be reasonable.

One of the greater challenges in this study was determining the direct costs in the country because of the difficulty of obtaining some centralized information on the resources used and costs. Therefore, it was decided to adapt the costs for each stage from the three possible scenarios: the first scenario was based on international guidelines for diabetes management issued by the International Diabetes Federation (16) and in accordance with the minimum management criteria, in which the cost was assigned according to Colombian references that were available for some of the stages (e.g., diabetes treatment with diet and exercise, oral and insulin treatment, and proteinuria treatment). The second cost scenario was the identification of local studies of annual costs per patient for acute myocardial infarct (first year and successive years) and for dialysis and 
TABLE 6. Mean total costs in millions of dollars and by disease stage, Colombia, 2007

\begin{tabular}{|c|c|c|c|}
\hline Health status & Direct cost ${ }^{a, b}$ & Indirect $\operatorname{cost}^{\mathrm{a}, \mathrm{c}}$ & Total cost ${ }^{a, b}$ \\
\hline $\begin{array}{l}\text { Controlled T2DM }{ }^{d} \text { patient } \\
\text { (diet and exercise, oral } \\
\text { treatment, and/or insulin } \\
\text { treatment) }\end{array}$ & 435 & 580 & 1015 \\
\hline Amputation & 86 & 66 & 152 \\
\hline Cardiac and coronary disease & 223 & 971 & 1194 \\
\hline Nephropathy & 23 & 10 & 33 \\
\hline Retinopathy & 18 & 87 & 105 \\
\hline Stroke & 137 & 73 & 210 \\
\hline Total & 921 & 1787 & 2708 \\
\hline
\end{tabular}

a Costs converted to U.S. dollars (44).

${ }^{b}$ Direct cost $=$ cost of treatment of T2DM and complications (e.g., drugs, labs, hospitalizations, professional care).

${ }^{c}$ Indirect cost $=$ costs for productivity loss per year in patients $<65$ years old, disability (progression diseases) patients $<65$

years, and productivity loss due to mortality in patients $<65$ years.

d T2DM = type 2 diabetes mellitus. renal transplant (first year). The third scenario adapted international costs for stages in which local information was not available, in which case we used purchasing power parities. This technique must be done with caution, since extrapolation of results to the Colombian scenario may be limited. However, an ap- proximation using the best available information was made.

On the other hand, determination of indirect costs used the human capital approach, assessing costs in Colombian pesos. This approach does have limitations, but it seems to be reasonable when considering that Colombia is a develop-
TABLE 7. Results of univariate sensitivity analyses in Colombia

\begin{tabular}{|c|c|c|c|c|}
\hline Variable & $\begin{array}{l}\text { Base } \\
\text { case }\end{array}$ & $\begin{array}{l}\text { Sensitivity } \\
\text { analysis }\end{array}$ & $\begin{array}{l}\text { Rationale and/or } \\
\text { reference }\end{array}$ & $\begin{array}{l}\text { Cost } \times \\
1000^{a}\end{array}$ \\
\hline Base case & & & & 21500 \\
\hline Age & 40 & $\begin{array}{l}50 \\
55 \\
60 \\
65 \\
70\end{array}$ & Cost of controlled T2DM ${ }^{b}$ patient & $\begin{array}{ll}20 & 168 \\
19 & 664 \\
18 & 883 \\
17020 \\
14879\end{array}$ \\
\hline Cost of $A M I^{b}$ first year ${ }^{a}$ & 10.073 & $\begin{array}{r}5000 \\
8750 \\
12500 \\
16250 \\
20000\end{array}$ & Cost of controlled T2DM patient & $\begin{array}{l}19285 \\
19500 \\
19715 \\
19930 \\
20145\end{array}$ \\
\hline Cost of stroke subsequent years ${ }^{a}$ & 873 & $\begin{array}{r}500 \\
875 \\
1250 \\
1625 \\
2000\end{array}$ & Cost of controlled T2DM patient & $\begin{array}{l}19576 \\
19576 \\
19576 \\
19576 \\
19576\end{array}$ \\
\hline Discount rate & 0.05 & $\begin{array}{r}0.01 \\
0.0275 \\
0.045 \\
0.0625\end{array}$ & 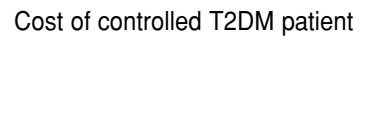 & $\begin{array}{l}21678 \\
20729 \\
19826 \\
18966\end{array}$ \\
\hline $\begin{array}{l}\text { Transition probability for controlled } \\
\text { T2DM patient with insulin }\end{array}$ & 0.023 & $\begin{array}{r}0.01 \\
0.015 \\
0.025 \\
0.03\end{array}$ & Cost of controlled T2DM patient & $\begin{array}{l}18330 \\
18807 \\
19769 \\
20255\end{array}$ \\
\hline $\begin{array}{l}\text { Transition probability for cardiac } \\
\text { and coronary disease }\end{array}$ & 0.0331 & $\begin{array}{l}0.01 \\
0.02 \\
0.04 \\
0.05\end{array}$ & Cost of controlled T2DM patient & $\begin{array}{l}20320 \\
19967 \\
19396 \\
19163\end{array}$ \\
\hline Transition probability for stroke & 0.0112 & $\begin{array}{l}0.005 \\
0.008 \\
0.016 \\
0.020\end{array}$ & Cost of controlled T2DM patient & $\begin{array}{ll}18 & 993 \\
19 & 352 \\
20 & 014 \\
20 & 321\end{array}$ \\
\hline
\end{tabular}

a Adjusted for inflation to year 2007 in Colombian pesos (U.S. \$1 = 2121 Colombian pesos) (26-28).

b $\mathrm{T} 2 \mathrm{DM}=$ type 2 diabetes mellitus, $\mathrm{AMI}=$ acute myocardial infarction. ing country with many other economic problems.

The total cost of disease (i.e., direct plus indirect costs) was calculated as the annual cost per patient. This value was then converted to the international reference standard (U.S. dollars) so that data may be compared with other published international studies. The mean direct cost per patient in this model was U.S. $\$ 288$, compared with the CODE-2 study performed in Spain by Mata et al. (10), in which the estimated value was approximately \$1 700 dollars (which converts to $\$ 407$ using purchasing parity) for the year 2002, which is greater than that determined for this study. In addition, the costs for services demanded by patients with more complications may be underestimated.

We conducted a further comparison of the resource use rate between our study and CODE-2 (24). In our model, the costs associated with treatment of diabetes accounted for $47 \%$ of the total costs, while the CODE-2 study reported $28 \%$. Similarly, the cost of complications in our study was $53 \%$ versus $30.5 \%$ in CODE-2. Superficially, these results appear to be discrepant; however, the CODE-2 study included an additional rate of $40.8 \%$ for "costs not related to diabetes." When that factor was removed, the cost proportion for diabetes treatment was $46 \%$ (virtually identical to our rate of $47 \%$ ) and for complications it was $64 \%$. Considering these adjusted rates, the studies are in good agreement.

When extrapolated to the population of Colombia, the annual cost was about $\$ 2700$ million (\$921 million in direct costs and \$1 770 million in indirect costs). These results compare well with those of Barceló et al. (15) in Latin American countries. They estimated that the total costs for Colombia were about $\$ 2580$ million (\$414 million in direct costs and \$2 171 million in indirect costs). Although the latter was estimated by indirect methods - that is, it did not include local costs-the total cost is very similar considering the difference in year of each study. However, there is a notable difference in direct and indirect costs for both studies.

The direct (34\%) and indirect $(66 \%)$ cost rates were in agreement with estimates from some international studies. However, there is some variability among the different published studies. Comparing the percentage results with other studies, 
we see a similar behavior, for example, with the model developed by the American Diabetes Association in 1997 (14). In that study, the proportions of direct and indirect costs were $45 \%$ and $55 \%$, respectively. Henriksson and Jonsson (46) estimated the total costs for T2DM for Sweden in 1994 with a rate for direct costs of $43 \%$ and for indirect costs of $57 \%$. The National Institute of Diabetes and Digestive and Kidney Diseases (47) study in 1995 reported a rate of $66 \%$ for direct costs and $34 \%$ for indirect costs.

\section{CONCLUSIONS}

We estimated that the annual cost of T2DM for Colombia is U.S. \$2 708 million from the societal perspective. From the Ministry of Health and the Colombian Health System perspective, the direct costs of health care per year were $\$ 911$ million. The annual direct cost per patient was U.S. \$288, and the indirect cost was U.S. $\$ 559$ (total $=\$ 847$ ). The cost of treating diabetes and macrovascular complications constitutes $86 \%$ of the direct costs and $95 \%$ of the indirect costs.

The results obtained in this study must be used with caution, taking into consideration the following points: Only the stages of the disease having the greatest impact on morbidity and mortality in Colombia were used. The costs of hypoglycemia, diabetic neuropathies, ketoacidosis, infections, and other complications were not considered, so the actual cost of the disease may well be greater. Also, the annual costs of other countries were adapted for several stages of the disease, although we did use purchasing power in an attempt to make them comparable. Cost estimations were based on the international guidelines for diabetes management issued by the International Diabetes Federation; however, physicians' compliance with these guidelines was not included. For that reason, further studies should be undertaken in order to quantify this effect.

Markov models allow for the management of uncertainty; however, it is a probabilistic model of disease progression and must be regarded as such. This Markov model was developed and adapted for Colombia, and the data reflect a rational progression of the disease that compares with international models. Also local variables that may influence health care quality such as health care system, social and economic aspects, and patient behavior were not considered in this study.

This study provides a basis for decision making by payers, government, and health care administrators that assists them in assigning costs for the treatment of T2DM. Likewise, because of the characteristics of the model, it can be adapted for epidemiologic and public health decision making.

The development of this type of research project in a country like Colombia represents a challenge because of scarce epidemiologic and cost information. However, this factor must not be an obstacle to developing future studies that allow for better decision making in health care. The economic burden of T2DM in Colombia is generally comparable to results from other countries.

Disclaimer. This paper was part of a master of science thesis done by Juan Camilo González in the Departamanto de Economía, Universitat Pompeu Fabra, Barcelona, Spain. The work was performed independently from his employer, Merck Sharp \& Dohme, Bogotá, Colombia, which bears no responsibility for this work. No external funding was received for this research from any source.

Acknowledgments. The authors thank Professor Juan Oliva, Departamento de Economía, Universidad Carlos III de Madrid, and Professor Pablo Aschner, endocrinologist, Universidad Javeriana, for advice and critical comments during this research.

\section{REFERENCES}

1. World Health Organization. Diabetes mellitus fact sheet no. 312. Geneva: WHO; 2006.

2. Sobel BE, Schneider DJ. Cardiovascular complications in diabetes mellitus. Curr Opin Pharmacol. 2005;5:143-8.

3. Grundy SM, Benjamin IJ, Burke GL, Chait A, Eckel RH, Howard BV, et al. Diabetes and cardiovascular disease: a statement for healthcare professionals from the American Heart Association. Circulation. 1999;100:1134-46.

4. Wannamethee SG, Shaper AG, Lennon L. Cardiovascular disease incidence and mortality in older men with diabetes and in men with coronary heart disease. Heart. 2004;90:1398-403.

5. Ettaro L, Songer TJ, Zhang P, Engelgau MM. Cost-of-illness studies in diabetes mellitus. Pharmacoeconomics. 2004;22:149-64.

6. Akobundu E, Ju J, Blatt L, Mullins CD. Costof-illness studies: a review of current methods. Pharmacoeconomics. 2006;24:869-90.

7. Oliva J, Lobo F, Molina B, Monereo S. Direct health care costs of diabetic patients in Spain. Diabetes Care. 2004;27:2616-21.

8. Taylor AK. Medical expenditures and insurance coverage for people with diabetes: estimates from the National Medical Care Expenditure Survey. Diabetes Care. 1987;10:87-94.
9. Massi-Bennedetti M, CODE-2 Advisory Board. The cost of diabetes type II in Europe, the CODE-2 Study. Diabetologia. 2002;45:S1-4.

10. Mata M, Antoñanzas F, Tafalla M, Sanz P. El coste de la diabetes tipo 2 en España. El estudio CODE-2. Gac Sanit. 2002;16:511-20.

11. Hart WM, Espinosa C, Rovira J. A simulation model of the cost of the incidence of IDDM in Spain. Diabetologia. 1997;40:311-8

12. Stern Z, Levy R. The direct cost of type 1 diabetes mellitus in Israel. Diabet Med. 1994;11: 528-33.

13. Aschner P. Diabetes trends in Latin America. Diabetes Metab Res Rev. 2002;18(Suppl 3): S27-31.

14. American Diabetes Association. Economic consequences of diabetes mellitus in the US in 1997. Diabetes Care. 1998;21:296-309.

15. Barceló A, Aedo C, Rajpathak S, Robles S. The cost of diabetes in Latin America and the Caribbean. Bull World Health Organ. 2003; 81(1):19-27.

16. International Diabetes Federation. Clinical Guidelines Task Force Global. Guideline for type 2 diabetes. Brussels: IDF; 2005.

17. Barceló A, Rajpathak S. Incidence and prevalence of diabetes mellitus in the Americas. Pan Am J Public Health. 2001;10:300-8.
18. World Health Organization. WHO statistical information system (WHOSIS). Life tables for WHO member states, Colombia 2004. Available from: http://www3.who.int/whosis/ life/life_tables/life_tables_process.cfm? country $=$ col\&language $=$ en\#. Accessed 3 April 2007.

19. Clarke PM, Gray AM, Briggs A, Farmer AJ, Fenn P, Stevens RJ, et al. A model to estimate the lifetime health outcomes of patients with type 2 diabetes: the United Kingdom Prospective Diabetes Study (UKPDS) Outcomes Model (UKPDS no. 68). Diabetologia. 2004;47: 1747-59.

20. United Kingdom Prospective Diabetes Study (UKPDS) Group. Intensive blood-glucose control with sulphonylureas or insulin compared with conventional treatment and risk of complications in patients with type 2 diabetes (UKPDS 33). Lancet. 1998;352:837-53.

21. O'Reilly D, Hopkins R, Blackhouse G, Clarke P, Hux J, Guan J, et al. Development of an Ontario diabetes economic model (ODEM) and application to a multidisciplinary primary care diabetes management program. Toronto: Ontario Ministry of Health and Long-Term Care; 2006 
22. Lamotte M, Annemans L, Lefever A, Nechelput M, Masure J. A health economic model to assess the long-term effects and costeffectiveness of orlistat in obese type 2 diabetic patients. Diabetes Care. 2002;25:303-8.

23. United States Renal Data System. The 2006 annual data report graphics as Microsoft PowerPoint $^{\mathrm{TM}}$ color slides. Available from: http://www.usrds.org/slides.htm. Accessed 4 April 2007.

24. Zhou H, Isaman DJ, Messinger S, Brown MB, Klein R, Brandle M, et al. A computer simulation model of diabetes progression, quality of life, and cost. Diabetes Care. 2005;28:2856-63.

25. World Health Organization. Purchase power parity, choosing interventions that are cost effective (WHO-CHOICE). Available from: http://www.who.int/choice/costs/ppp/ en/index.html. Accessed 4 April 2007.

26. Banco de la República. Reportes de inflación en Colombia, informes sobre inflación. Bogotá: Banco de la Republica; 2005. Available from: http://www.banrep.gov.co/. Accessed 4 April 2007.

27. Banco de la República. Reportes de inflación en Colombia, informes sobre inflación. Bogotá: Banco de la Republica; 2006. Available from: http://www.banrep.gov.co/. Accessed 4 April 2007.

28. Banco de la República. Reportes de inflación en Colombia, informes sobre inflación. Bogotá: Banco de la Republica; 2007. Available from: http://www.banrep.gov.co/. Accessed 4 April 2007.

29. Ministerio de Proteccion Social. Lista de precios de medicamentos y procedimientos quirurgicos y hospitalarios. Decreto 2423 of 2005. Bogota: Diario Oficial; 2005

30. Farmaprecios. Guía de precios sugeridos al público, promedio de y para farmacias depen- dientes. 93rd ed. Bogota: Thomson PLM, S.A.; 2007.

31. Instituto Nacional de Cancerología Subdirección de Investigaciones, Vigilancia Epidemiológica y Registro. Costos unitarios de la atención médica del infarto agudo del miocardio, cáncer de pulmón y epoc atribuibles al consumo de tabaco en Colombia, Instituto Nacional de Cancerológica y PAHO. Bogota: Instituto Nacional de Cancerología Subdirección de Investigaciones, Vigilancia Epidemiológica y Registro; 2006. Pp. 15-17.

32. Oliva J, Lobo F, Molina B, Monereo S. Estudios de los costes directos sanitarios de los pacientes con diabetes mellitus en España. Working papers 04-03. Economic series 01. Madrid: Universidad Carlos III de Madrid; 2004.

33. Arós F, Loma-Osorio A, Alonso A, Alonso JJ, Cabadés A, Coma-Canella I, et al. Guías de actuación clínica de la Sociedad Española de Cardiología en el infarto agudo de miocardio. Rev Esp Cardiol. 1999;52:919-56.

34. Antoñanzas F, Anton F, Echevarria I, Juarez C. Clínica y epidemiologia de la insuficiencia cardiaca congestiva (ICC): un análisis de costes. Clín Cardiovasc. 1998;16:27-34.

35. Lamas J, Alonso M, Saavedra J, Garcia-Trio G, Rionda M, Ameijeiras M. Costes de la diálisis crónica en un hospital público: mitos y realidades. Nefrologia. 2001;21:283-94.

36. Instituto del Seguro Social. Lista de precios de prestación servicios de salud del Instituto del Seguro Social. Acuerdo 312 de 2004. Bogota: Diario Oficial; 2004.

37. Chicaíza L. Fallas del mercado de la salud en Colombia: el caso de la insuficiencia renal crónica. Rev Econ Inst. 2005;7(12):191-208.

38. Palmer AJ, Annemans L, Roze S, Lamotte M, Rodby RA, de Alvaro F, et al. Coste-efectividad de irbesartan en pacientes hipertensos con nefropatía diabética tipo II: una perspectiva Española. Nefrología. 2004;23:231-8.

39. Ray JA, Valentine WJ, Secnik K, Oglesby AK, Cordony A, Gordois A, et al. Review of the cost of diabetes complications in Australia Canada, France, Germany, Italy and Spain. Curr Med Res Opin. 2005;10:1617-29.

40. Mattke S, Balkrishnan A, Bergamo G, Newberry SJ. A review of methods to measure health-related productivity loss. Am J Manag Care. 2007;13:211-7.

41. Mayfield J, Deb P, Whitecotton L. Work disability and diabetes. Diabetes Care. 1999;22: 1105-9.

42. Von Korff M, Katon W, Lin EH, Simon G, Ciechanowski P, Ludman E, et al. Work disability among individuals with diabetes. Diabetes Care. 2005;28:1326-32.

43. United Nations Children's Fund. Colombiastatistics, basic indicators. New York: UNICEF 2005. Available from: http://www.unicef. org/infobycountry/colombia_statistics.html? $\mathrm{q}=$ printme. Accessed 16 April 2007.

44. Banco de la República. Tasa de cambio 23 Abril de 2007. Available from: http://www. banrep.gov.co/. Accessed 23 April 2007.

45. Departamento Nacional de Estadística DANE. Población compensada censo general 2005 contador de población. Bogota: DANE; 2007. Available from: http://www.dane.gov.co/ reloj/reloj_animado.php. Accessed 21 April 2007.

46. Henriksson F, Jonsson B. Diabetes: the cost of illness in Sweden. J Intern Med. 1998;244:461-8.

47. National Institutes of Health. Disease-specific estimates of direct and indirect costs of illness and NIH support. Bethesda: NIH; 1995.

Manuscript received on 11 August 2008. Revised version accepted for publication on 6 January 2009

RESUMEN Objetivo. Determinar el costo de la enfermedad, total y por paciente, de la diabetes mellitus tipo 2 (DM2) en Colombia desde las perspectivas de la sociedad y del Ministerio de Salud. Métodos. A partir de la experiencia clínica de un endocrinólogo colombiano se adaptó Diabetes mellitus tipo 2
en Colombia:
costo de la enfermedad para Colombia un modelo de transición de Markov ya publicado. Las probabilidades de transición para el modelo se tomaron de una revisión de la literatura internacional. Se elaboró un modelo para un horizonte temporal de 42 años. Se identificaron los recursos directos (por medicamentos, laboratorio, médicos, hospitalización y otros servicios de salud) y se estableció su costo a partir de la lista nacional de precios, las directivas internacionales de atención, y otros estudios colombianos o de otros países. Los costos indirectos (tiempo de trabajo perdido) se calculó mediante el enfoque de capital humano. Los costos directos e indirectos - tanto anuales como por toda la vida- se determinaron en dólares estadounidenses (US\$) de 2007 con una tasa de descuento de 5\%, tanto para un paciente como su proyección para toda la población colombiana. Los costos se agruparon según el tratamiento y el curso de la enfermedad.

Resultados. El costo estimado anual fue de US\$2 700 millones desde la perspectiva de la sociedad y de US\$ 921 millones desde la perspectiva del Ministerio de Salud. Los costos directos anuales por paciente fueron de US\$288, mientras que los indirectos fueron US\$ 559 (total $=$ US\$ 847). Estos costos se distribuyeron según el curso de la enfermedad de la siguiente manera: $47 \%$ por el tratamiento de la diabetes (medicamentos); $24 \%$ por enfermedades cardíacas y coronarias; $15 \%$ por accidentes cerebrovasculares; $9 \%$ por amputaciones; $3 \%$ por nefropatías; y $2 \%$ por retinopatías. Las complicaciones macrovasculares constituyeron $86 \%$ de los costos directos anuales y $95 \%$ de los indirectos.

Conclusiones. Se estimó el costo anual de la DM2 para Colombia según las perspectivas de la sociedad, el Ministerio de Salud y el Sistema de Salud de Colombia. También se estimaron los costos directos anuales por paciente y el costo del tratamiento de la diabetes y sus complicaciones macrovasculares. La carga económica es considerable y comparable a la informada en otros países. El modelo mostró una progresión lógica de la enfermedad.

Palabras clave Costo de enfermedad, diabetes mellitus, Colombia, América Latina. 